\title{
Presença do acompanhante no parto e nascimento em meio a pandemia Covid-19: representações de puérperas
}

The presence of the escort in childbirth and birth in the Covid-19 pandemic: representations of puerperal women

La presencia de la acompañante en el parto y el nacimiento en la pandemia de Covid-19: las representaciones de las mujeres puérperas

Juliane Pagliari Araujo ORCID: https://orcid.org/0000-0001-7821-6731 Universidade Estadual de Londrina, Brasil Instituto Federal do Paraná, Brasil E-mail:juliane.pagliari@uel.br

Rafaela Sterza da Silva ORCID: https://orcid.org/0000-0002-4049-475X Universidade Estadual de Londrina, Brasil E-mail: rafasterza@hotmail.com Ludmilla Laura Miranda ORCID: https://orcid.org/0000-0002-8056-5551 Universidade Estadual de Londrina, Brasil E-mail: m.ludmilla@hotmail.com Carolina Mathiolli

ORCID: https://orcid.org/0000-0002-2631-8637 Universidade Estadual de Londrina, Brasil Centro Universitário Filadelfia, Brasil E-mail: carolina_mathiolli@hotmail.com Milena Torres Guilhem Lago ORCID https://orcid.org/0000-0002-7735-5905 Universidade Estadual de Londrina, Brasil E-mail: milena_mtg@hotmail.com

Adriana Valongo Zani

ORCID https://orcid.org/0000-0002-6656-8155 Universidade Estadual de Londrina, Brasil E-mail: adrianazanienf@gmail.com

\begin{abstract}
Resumo
Objetivo: Apreender as representações de puérperas frente à experiência do parto e à manutenção do direito ao acompanhante em meio a pandemia Covid-19. Metodologia: Estudo descritivo com abordagem qualitativa fundamentado no referencial da Teoria das Representações Sociais com análise metodológica do Discurso do Sujeito Coletivo. As participantes do estudo foram 69 puérperas, cujos filhos nasceram durante a pandemia Covid-19, maiores de 18 anos, com acesso à internet. Realizou-se a coleta de dados entre os meses de abril a julho de 2020, por meio de um instrumento semiestruturado disponibilizado via Google Forms ${ }^{\circledR}$. Resultados e Discussão: Sessenta e nove puérperas participaram deste estudo, com idade média de vinte e sete anos. Dos discursos emergiram quatro ideias centrais: 1) Acompanhante como alicerce; 2) Privação do direito ao acompanhante; 3) Pandemia não deve excluir a presença do acompanhante; 4) Desinformação sobre a pandemia. Conclusão: Apreender as representações das puérperas frente à sua experiência no parto durante a pandemia Covid-19 faz-se necessário para refletir sobre a necessidade de garantia dos direitos das mulheres, bem como promover uma assistência de qualidade à sua saúde e de seus filhos.
\end{abstract}

Palavras-chave: Covid-19; Parto; Acompanhante de paciente; Trabalho de parto.

\begin{abstract}
Objective: Apprehending the representations of puerperal women in the face of the experience of childbirth and the maintenance of the right to the companion in the midst of the Covid-19 pandemic. Methodology: A descriptive study with qualitative approach based on the reference of the Theory of Social Representations with methodological analysis of the Collective Subject Discourse. The study participants were 69 puerperal women, whose child was born during the Covid-19 pandemic, over 18 years old, with internet access. Data were collected between April and July 2020, through a semi-structured instrument made available via Google Forms ${ }^{\circledR}$. Results and Discussion: Sixty-nine puerperals participated in this study, of an average age of twenty-seven years old. From the discourses emerged four central ideas:
\end{abstract}


1) Companion as a foundation; 2) Deprivation of the right to the companion; 3) Pandemic should not exclude the presence of the companion; 4) Misinformation about the pandemic. Conclusion: apprehending the representations of postpartum women in front of their experience in childbirth during the Covid-19 pandemic is necessary to reflect on the need to guarantee women's rights, as well as to promote quality care for their health and their children.

Keywords: Covid-19; Childbirth; Patient companion; Birth-labor.

\section{Resumen}

Objetivo: Aprehender las representaciones de las puérperas frente a la experiencia del parto y el mantenimiento del derecho a la acompañante en medio de la pandemia del Covid-19. Metodología: Un estudio descriptivo con enfoque cualitativo basado en la referencia de la Teoría de las Representaciones Sociales con análisis metodológico del Discurso del Sujeto Colectivo. Las participantes del estudio fueron 69 mujeres puérperas, cuyo hijo nació durante la pandemia de Covid-19, mayores de 18 años, con acceso a la internet. Los datos fueron recolectados entre abril y julio de 2020, a través de un instrumento semiestructurado disponible a través de Google Forms ${ }^{\circledR}$. Resultados y Discusión: Sesenta y nueve puérperas participaron en este estudio, con una edad promedia de veintisiete años. De los discursos surgieron cuatro ideas centrales: 1) El compañero como fundamento; 2) Privación del derecho al acompañante; 3) La pandemia no debe excluir la presencia del acompañante; 4) Desinformación de la pandemia. Conclusión: Aprehender las representaciones de las mujeres posparto frente a su experiencia en el parto durante la pandemia del Covid-19 es necesario para reflexionar acerca de la necesidad de garantizar los derechos de las mujeres, así como de promover una atención de calidad para su salud y la de sus hijos.

Palabras clave: Covid-19; Parto; Acompañante del paciente; Trabajo de parto.

\section{Introdução}

A gestação é um momento idealizado na vida de muitas mulheres, um período cheio de descobertas e expectativas em relação ao nascimento, crescimento e desenvolvimento da criança. O parto é um dos períodos mais impactantes e emocionantes para as gestantes, pois ao mesmo tempo que irá conhecer o maior amor do mundo, vivenciará momentos de grandes riscos junto com seus bebês (Tostes \& Seidl, 2016; Rodrigues et al., 2020). Este momento é considerado um momento de insegurança, pois a mulher é afastada da sua rotina, inserida em um novo ambiente passando a ser avaliada por diferentes profissionais de saúde a todo instante (Souza et al., 2020; Rodrigues et al., 2020).

A hospitalização é um processo necessário para vigilância e acompanhamento da gestação, que eventualmente modifica e intensifica de acordo com a particularidade da gestante e do seu filho. Nascimento de bebês pré-termo, que precisam de internação, suporte e cuidados intensivos estão cada vez mais frequentes, assim como a sobrevida deles. Porém, o período de internação retrata momentos de insegurança, incerteza e muita angústia para todos os familiares, principalmente a mãe que vai embora sem seu filho nos braços (Miranda et al., 2021; Souza et al., 2020; Rodrigues et al., 2020).

É responsabilidade da equipe de enfermagem durante sua rotina desenvolver diferentes atividades, e dentre elas um cuidado humanizado com a finalidade de diminuir esses sentimentos de ambivalência para os pacientes e familiares (Mesquita et al., 2019; Miranda et al., 2021). Tem-se que o cuidado integral e direitos do paciente devem estar presente em todos os momentos da hospitalização do binômio mãe/bebê, mesmo em situações de pandemia, como da Covid-19.

Os primeiros casos de Covid-19 surgiram em dezembro de 2019 na cidade de Wuhan, na China e foi declarada pela Organização Mundial da Saúde como a sexta emergência de saúde pública. Sua disseminação vem causando muitas mortes, sequelas e consequências a toda população, principalmente aos mais vulneráveis, como as gestantes, que devido às alterações na imunofisiologia tornam-se mais suscetíveis à doença (Who, 2020; Brasil, 2021).

Durante este tempo de emergência sanitária, ocorreram inúmeros casos de violação dos direitos das mulheres e de seus filhos no campo de parto, nascimento e hospitalização, tais como a privação de um acompanhante durante o período do parto e nascimento. Assim, tem-se como pergunta de pesquisa: Como as puérperas vivenciaram a experiência do parto e presença do acompanhante, durante esse momento, na pandemia Covid-19? Diante deste contexto, o objetivo desse estudo foi apreender as representações de puérperas frente a experiência do parto e a manutenção do direito ao acompanhante em meio a pandemia Covid-19. 


\section{Metodologia}

Trata-se de um estudo descritivo, com abordagem qualitativa, fundamentado no referencial da Teoria das Representações Sociais, que realiza uma interpretação da realidade e pressupõe que não há distinção entre sujeito e objeto da pesquisa, ou seja, constituem uma série de opiniões, explicações e afirmações produzidas com base no cotidiano dos grupos e tem como base que toda realidade é representada pelo indivíduo, toda representação é, portanto, uma forma de visão global e unitária de um objeto (Jodelet, 2005).

As participantes do estudo foram 69 puérperas, cujo filho nasceu durante a Pandemia da Covid-19, maiores de 18 anos, com acesso à internet.

Realizou-se a coleta de dados entre os meses de abril a julho de 2020, por meio de um instrumento semiestruturado elaborado especificamente para essa pesquisa. Em um primeiro momento, foi realizado um teste piloto para validação do instrumento. O pesquisador responsável fez cadastro em redes sociais de grupos de gestantes, que tinham como objetivo partilhar informações sobre recém-nascidos, grupos de enfermeiros obstétricos, prematuridade ou neonatologia, e, após aceite para participar dessas redes sociais, foi solicitada permissão para postar o link de acesso ao estudo, e, também que esse link fosse compartilhado por todos. O convite e o link de acesso ao formulário eletrônico disponibilizado na plataforma Google Forms®, o qual foram direcionadas à leitura do Termo de Consentimento Livre e Esclarecido e somente após o aceite acessaram o instrumento de coleta de dados.

Utilizou-se roteiro composto por perguntas abertas e fechadas, para possibilitar que o entrevistado discorresse sobre o assunto em questão sem se restringir à questão colocada (Minayo, 2016). As variáveis de interesse foram: idade, profissão, renda familiar, estado de residência, acompanhante no momento do parto. No instrumento da entrevista apresentou-se as questões norteadoras: Qual sua opinião em relação a ter direito ou não a um acompanhante neste momento que estamos vivenciando a pandemia pela Covid-19? Se você pudesse escolher em relação a poder permitir ou não um acompanhante, qual seria sua escolha? E Por quê?

Para apreender as representações de puérperas frente à experiência do parto e a manutenção do direito ao acompanhante em meio a pandemia Covid-19, a análise metodológica escolhida foi o Discurso do Sujeito Coletivo (DSC), pois permite uma aproximação com o fenômeno em estudo. O DSC é elaborado por meio de fragmentos de vários discursos individuais e deve ser escrito no tempo verbal da primeira pessoa do singular de modo que represente uma ideia coletiva (Lefevre, et al., 2009). Foram utilizadas três figuras metodológicas: as expressões-chave (E-ch), a ideia central (IC) e o discurso do sujeito coletivo (DSC). As E-ch são trechos literais do depoimento. A IC é o detalhamento dos significados que há nas falas.

As entrevistas individuais foram analisadas repetidamente, sendo que cada escrita foi lida e relida, imergindo os pesquisadores nos discursos, a fim de identificar as E-ch e, em seguida, as IC. Para a formulação do DSC, foram agrupadas as E-ch de maneira que formassem um discurso coerente.

As falas agrupadas foram caracterizadas pela letra $\mathrm{P}$ (participante) seguida do numeral referente à ordem de execução e envio das respostas.

O estudo foi aprovado pelo Comitê de Ética em Pesquisa (CEP) com seres humanos sob o Parecer n. 4.023 .898 e o Certificado de Apresentação para Apreciação Ética (CAAE) n. 31528920.9.0000.5231, e foi conduzido de acordo com os padrões éticos.

\section{Resultados}

Sessenta e nove puérperas participaram deste estudo. Quanto à idade, a média foi de vinte e sete anos, sendo a idade mínima relatada de quinze anos e a idade máxima de quarenta e cinco anos. 
Em relação a renda familiar, oito das participantes relataram renda menor que um salário mínimo, 35 possuíam rendimento de um a dois salários mínimos, 14 de dois a quatro salários mínimos, oito participantes referiram renda familiar menor que um salário mínimo e 12 das entrevistadas rendimento maior que quatro salários mínimos.

As entrevistadas residiam em sua maioria (33\%) no sudeste do país, seguido pela região sul (31\%), nordeste (16\%), norte (14\%), e centro-oeste (6\%).

Das 69 participantes desse estudo, 49 referiram que no momento do parto foi permitido a presença de acompanhante, sendo que 31 das puérperas foram acompanhadas pelo companheiro, 10 pelo pai da criança, três pela tia do recém-nascido e cinco pela avó do neonato.

A análise dos discursos das participantes possibilitou apreender as representações frente a experiência do parto e da manutenção do direito ao acompanhante em meio a pandemia Covid-19.

Dessa forma, emergiram quatro ideias centrais: 1) Acompanhante como alicerce; 2) Privação do direito ao acompanhante; 3) Pandemia não deve excluir a presença do acompanhante; 4) Desinformação sobre a pandemia.

\section{IC1 - Acompanhante como alicerce}

A vivência do momento do parto e pós-parto foi representado pelas puérperas como ambivalente. Os significados sobre o parto são positivos e se expressam como um acontecimento único para a mulher, especial e alegre. Entretanto, experiências negativas como medo e aflição, limitação para o cuidado com o recém-nascido, vulnerabilidade e fragilidade, esforço físico e mental são manifestados nos discursos das participantes. Diante desse misto de representações acerca do parto e pós-parto, o papel do acompanhante é sólido e significa para as puérperas participantes um mecanismo de enfrentamento e superação, revelado mediante ao apoio emocional, ajuda com os cuidados do recém-nascido, suporte familiar, segurança e viabilização dos desejos da mulher em relação ao parto.

DSC1 - É um momento de medo e alegria junto, de bastante fragilidade pra mãe, com vivências únicas e dolorosas. Um momento delicado, de aflição e de muito esforço físico e mental. A parturiente está vulnerável. Ter uma pessoa de confiança, para dar suporte, é primordial (P6, P19, P61, P63, P67).

DSC2 - É um momento delicado, um momento único. A mulher está mais frágil e debilitada neste momento da maternidade, precisamos pelo menos de alguém para nos ajudar com os cuidados com o recém-nascido, suporte e apoio familiar em um momento tão especial como esse (P5, P26, P49, P37).

DSC3 - É um momento especial, delicado e difícil para ser passado sozinha. O acompanhante é importante, sem ele, não conseguiria dizer o nosso plano de parto e ele sabia todas as minhas vontades, já estamos sensíveis, precisamos de suporte, de apoio de quem a gente ama. Um rosto familiar ajuda a ter controle emocional, se sentir bem e não solitária (P6, P11, P25, P36, $\mathrm{P} 48, \mathrm{P} 58, \mathrm{P} 60)$.

\section{IC2 - Privação do direito ao acompanhante}

A privação ao direito do acompanhante é representa pelas puérperas com falta de respeito e humanização, que são expressados por sentimento e experiência de revolta, incompreensão, sofrimento, abandono, medo, desespero, solidão e fragilidade.

DC1 - Não tive ninguém para me ajudar no hospital, fiquei sozinha, me senti abandonada e com medo, por ser mãe de primeira viagem e por estar em um hospital nesse momento de pandemia. Achei uma falta de humanização pois estamos operada e precisamos de ajuda para se levantar da cama, e ficamos sozinhas sem nenhum apoio (P1, P13, P15). 
DC2 - Eu achei uma falta de respeito com as mamães, pois é um momento muito delicado, e eu senti muita a falta do meu marido comigo lá na hora. Foi difícil, pois eu chorei muito por meu marido não presenciar o parto da filha dele. É revoltante $(\mathrm{P} 12, \mathrm{P} 14)$.

\section{IC3 - Pandemia não deve excluir a presença do acompanhante}

As participantes compreendem os riscos em relação à Covid-19 e entendem ser necessário tomar os cuidados necessários, porém a pandemia, para eles não exclui a importância e o direito da presença do acompanhante, tanto para a mãe quanto para o pai.

DC1 - Em relação a Covid-19, o acompanhante deve tomar todas as medidas necessárias contra o vírus, mas a proteção é algo que já é exigida no hospital, antes mesmo de existir o vírus. Tem que ter direito sim, independente da pandemia, pois o acompanhante é do mesmo ambiente da residência então a mãe já tem o contato com a pessoa e é um momento único para uma mãe estar na sala só. É muito importante o acompanhante nesse momento, pois a lei permite o acompanhamento e os hospitais não cumprem (P8, P14, P53, P63).

DC2 - É importante e fundamental ter um acompanhante sim, com todos os cuidados possíveis, pois é um momento que só a experiência revela muita coisa. E isso é ótimo para o pai esse primeiro contato. Uma criança precisa de seus pais para sentirem segurança. O acompanhante deve ficar no hospital e não sair até o bebê receber alta (P9, P21, P23, P24).

\section{IC4 - Desinformação acerca da pandemia}

Mesmo quando o direito ao acompanhante não foi negado, a privação do direito à informação leva as mulheres a rejeitar a presença do acompanhante. Há aquelas que concordam com a instituição de saúde em proibir o acompanhante durante o parto e pós-parto. Para essas, mesmo sendo um momento difícil, preferem enfrentar a situação sozinha por medo do contágio, como medida de segurança para o recém-nascido, para redução de danos e garantir distanciamento.

DC1 - Escolhi não ter acompanhante, pois quanto mais gente maior o risco de contágio, estamos em uma época difícil, temos que nos prevenir, manter o distanciamento. Está bem triste passar por essa fase sem um acompanhante, mas entendo que é por uma boa causa e devemos respeitar e estar sempre se prevenindo (P51, P66).

DC2 - Confesso que foi difícil, mas ainda não permitiria não, pois já tem o pessoal da área de saúde indo e vindo todos os dias, por precaução a todos, é melhor. Essa pandemia está demais, é melhor se prevenir do que causar danos aos próximos (P51, P64).

\section{Discussão}

Os discursos das puérperas demonstraram que o momento do parto gera sentimentos ambivalentes. Visto que o processo de nascimento é cercado de diversos sentimentos para a parturiente, dentre eles, destacam-se a felicidade em se ter um bebê, dor, medo, prazer e alívio após o nascimento (Rolim, 2021). A presença do acompanhante reduz a solidão, estresse e ansiedade da mulher, encorajando-a e proporcionando conforto neste momento tão importante de suas vidas (Araújo, et al, 2021).

O nascimento de um filho é um momento único no arranjo familiar, assim, o cuidado humanizado e o atendimento aos direitos humanos, para essa família, deve ser preservado. Os profissionais de saúde devem garantir o cuidado integral e na condição de fragilidade da família, como o nascimento de um filho prematuro, essa família necessita de acolhimento (Borges et 
al., 2020). Faz-se necessário que as mulheres tenham acompanhantes durante todo o trabalho de parto, parto e pós-parto, incluindo pessoas de apoio confiáveis, e, profissionais de saúde qualificados (Who, 2018).

A pandemia da Covid-19, de modo geral, provoca sentimentos de medo referentes ao: isolamento social, contágio, transmissão vertical, aumento de estresse, problemas emocionais, principalmente, durante a gestação que é marcado por um período de grande instabilidade emocional (Arrais et al., 2021). A pandemia tem desencadeado várias preocupações devido à suspensão do direito da mulher ao acompanhante durante o trabalho de parto, parto e pós-parto.

No depoimento das participantes observou-se que durante a pandemia algumas maternidades privaram as mulheres de acompanhante durante o momento de parturição, bem como, algumas mulheres optaram pela não presença de acompanhante nesse momento único, devido ao medo do risco do contágio.

Estes dados corroboram à um estudo realizado com 1049 mulheres, dentre elas gestantes e puérperas das cinco regiões do país, no qual 79\% das gestantes se preocupavam em não poder ter acompanhante no pré-parto e durante o trabalho de parto e $88 \%$ se preocupavam em ficar sem o acompanhamento no pós-parto imediato. Estes dados possuem índices maiores que: medo do bebê ou de ela própria de contrair a Covid-19, medo de morrer, medo de sofrer violência obstétrica dentre outros. Outros dados que chamam a atenção são os casos de puérperas positivas para Covid-19, que referem medo de não poder amamentar (69\%) e não poder fazer o contato pele a pele (70\%) logo após o nascimento de seu bebê (Arrais et al., 2021).

O direito ao acompanhante no momento do parto é defendido na Lei Federal $\mathrm{n}^{\mathrm{o}} 11.108 / 2005$, por mais que a parturiente esteja com Covid-19 e que haja restrições no ambiente hospitalar. Salienta-se, nesse momento de pandemia, a necessidade de redução do número de pessoas presentes no momento do parto e também, que, a pessoa escolhida como acompanhante, deve ser assintomática para a Covid-19. Como enfatiza a Declaração da International Confederation of the Midwive (ICM) intitulada "Os direitos das mulheres no parto devem ser mantidos durante a pandemia" A declaração afirma e garante que é direito da mulher receber durante o trabalho de parto e nascimento atenção qualificada em uma rede de atenção à saúde, atendimento integral e humanizado, assim como ter um acompanhante de sua escolha num momento tão significativo e cheio de transformações (ICM, 2020; Souza, et al., 2020; Brasil, 2005), sendo um marco referencial para a garantia ao atendimento às necessidades de mulheres e seus filhos, num momento único de suas vidas (Brasil, 2005; Arrais et al., 2021, ICM, 2020).

É preciso considerar que a crise causada pela pandemia deverá impactar a qualidade do cuidado, refletindo na suspensão de acompanhante e outras práticas como realização de intervenções obstétricas desnecessárias, aumento de taxas de cesarianas, o desencorajamento do contato pele a pele e amamentação em casos suspeitos ou confirmados de puérperas com diagnóstico de Covid-19, sob justificativa de serem práticas potencialmente inseguras. (Souto, et al, 2020, Souza et al., 2020). Tem-se que tais práticas podem refletir de forma negativa na experiência reprodutiva das mulheres, na saúde de seus bebês, famílias e comunidade (Souza et al, 2020). No entanto, a recomendação do Ministério da Saúde; da Sociedade Brasileira de Pediatria, o Fundo das Nações Unidas para a Infância (UNICEF) é que o aleitamento materno deve ser estimulado e promovido, independentemente das mães suspeitas ou confirmadas para Covid-19, devido aos benefícios e o papel insignificante na transmissão de outros vírus respiratórios pelo leite (Brasil, 2020; SBP, 2020; Unicef, 2020).

Frente à necessidade de distanciamento social recomendado devido a pandemia Covid-19, faz-se necessário uma rede de apoio às puérperas para o sucesso da amamentação. Nesse sentido, a presença do acompanhante ou companheiro é apontada como um fator que promove melhor efetividade no processo de amamentação, estimulando o vínculo entre o recém-nascido e a mãe (Dantas et al., 2020). Além disso, destaca-se o papel do enfermeiro como participante da equipe multiprofissional, o qual deve estar desenvolvendo ações a fim de garantir o cuidado integral à puérpera e sua família.

As limitações deste estudo envolvem a escassez de evidências científicas sobre a temática abordada, ou seja, a experiência das puérperas durante a pandemia Covid-19 e a restrição de informações disponíveis por tratar-se de um assunto novo, no qual as pesquisas ainda estão sendo encaminhadas. As entrevistas foram realizadas via formulário online, então, elas 
retratam a percepção de um público específico de mulheres sobre suas experiências através de seus relatos escritos, que não necessariamente são as mesmas percepções de um outro grupo de mulheres.

\section{Considerações Finais}

Apreender as representações das puérperas frente à presença do acompanhante no parto e nascimento em meio a pandemia Covid-19 faz-se necessário para refletir sobre a necessidade de garantia dos direitos das mulheres, bem como, promover uma assistência de qualidade à sua saúde e de seus filhos. Além de garantir o cumprimento de leis e dos programas de assistência à saúde. Apesar das circunstâncias limitadas sobre estudos a respeito do conteúdo, considera-se que as observações contempladas no presente estudo são, de fato, relevantes para o amplo entendimento sobre a necessidade de garantia dos direitos das mulheres, visto que em nenhum momento independente das culturas e países ocorreu qualquer alteração no direito ao acompanhante neste momento, desta forma, necessário que os profissionais e instituições sejam capacitados e conscientizados que a Lei do direto ao acompanhante é soberana e está acima de normas criadas pelas instituições que prestam assistência a parturiente e puérpera.

\section{Referências}

Araújo, W. B. X. de, Barbosa, S. S. de S., Silva, A. M. da, Santos, L. C. dos, Silva, M. G. V. da, Andrade, A. R. L. de, Araújo, H. V. S., \& Oliveira, C. D. B. de. (2021). Influência das práticas integrativas e complementares durante o trabalho de parto: uma revisão integrativa. Revista Eletrônica Acervo Enfermagem, 13, e7749. https://doi.org/10.25248/reaenf.e7749.2021

Arrais, A.; Amorim, B.; \& Haidar, A C. (2021). Impacto psicológico da pandemia em gestantes e puérperas. Daphora,1(1). http://sprgs.org.br/diaphora/ojs/index.php/diaphora/article/view/219/235

Borges, T. P., Anjos, K. F., Ferraz, M. O. A., Silva, J. M. Q., Rosa, D. O. S \&Nascimento Sobrinho, C. L. (2020) Vivência de profissionais de enfermagem no respeito aos direitos humanos nas relações de cuidado. Revista de Enfermagem do Centro-Oeste Mineiro. 10:e4052. http://doi.org/10.19175/recom.v10i0.4052

Brasil. (2005). Lei $\mathrm{n}^{\circ}$ 11.108, de 7 de abril de 2005. Altera a Lei $\mathrm{n}^{\circ}$ 8.080, de 19 de setembro de 1990, para garantir às parturientes o direito à presença de acompanhante durante o trabalho de parto, parto e pós-parto imediato, no âmbito do Sistema Único de Saúde - SUS. https://legis.senado.leg.br/norma/570557/publicacao/15722854

Brasil. 2020. Ministério da Saúde. Secretaria de Atenção Primária à Saúde. Fluxo de Decisão para Amamentação no contexto da COVID-19. https://portaldeboaspraticas.iff.fiocruz.br/atencao-crianca/covid-19-e-aleitamento-materno-orientacoes-da-sbp-e-rblh/

Brasil. Agência Nacional de Vigilância Sanitária, ANVISA, (BR). (2021). Nota técnica VIMS/GGTES/ANVISA no 04/2020. Orientações para serviços de saúde: medidas de prevenção e controle que devem ser adotadas durante a assistência aos casos suspeitos ou 23 confirmados de infecção pelo novo coronavírus (SARSCoV-2). 4. http://portal.anvisa.gov.br/documents/33852/271858/Nota+T\%C3\%A9cnica+n+04-2020+GVIMS-GGTES-ANVISA/ab598660-3de4-4f14-8e6fb9341c196b28

Dantas, A., Santos, W., Nascimento, A., \& Oliveira, L. (2020). Refletindo sobre o contexto da amamentação durante a pandemia do COVID-19. Enfermagem em Foco, 11(2.ESP). https://doi.org/10.21675/2357-707X.2020.v11.n2.ESP.3616

International Confederation of Midwives (ICM). 2020. Women's rights in childbirth must be upheld during the coronavirus pandemic. https://www.internationalmidwives.org/assets/files/news-files/2020/03/icm-statement_upholding-womens-rightsduring-covid19-5e83ae2ebfe59.pdf.

Jodelet, D. (2005). Loucuras e representações sociais. Vozes.

Lefevre, F., Lefevre, A. M. C., \& Marques, M. C. C. (2009) Discurso do sujeito coletivo, complexidade e auto-organização. Ciênc Saúde Coletiva, 14(4). https://dx.doi.org/10.1590/S1413-81232009000400025

Mesquita, D. S., Naka, K. S., Kawamura, A. P. S., \& Schmidt, A. S. (2019). Acolhimento de Enfermagem na Unidade de Terapia Intensiva neonatal segundo binômio pais-filhos: estudo de revisão integrativa da literatura. Revista Eletrônica Acervo Saúde, 13, e980-e980. 10.25248/reas.e980.2019

Minayo, M. C. S. (2016). Ciência, técnica e arte: Desafio da pesquisa social. In: Deslandes, S.F., Cruz Neto, O., Gomes, R., Minayo, M.C.S. Pesquisa social: teoria, método e criatividade. Petrópolis (RJ): Vozes, 9-29.

Miranda, L. L., Silva, R. S., Ferrari, R. A. P., Assunção, R. C., \& Zani, A. V. (2021). Fatos em fotos: significado paterno sobre o filho prematuro na unidade neonatal. Brazilian Journal of Development, 7(1), 2-15. 10.34117/bjdv7n1-001

Rodrigues, A. R. M., Rodrigues, D. P., Silveira, M. A., Paiva, A. M., Fialho, A. V., \& Queiroz, A. B. (2020). Hospitalização na gravidez de alto risco: representações sociais das gestantes. Revista de Enfermagem Referência, 5(3), e20040. 10.12707/RV20040 
Research, Society and Development, v. 11, n. 3, e9611326188, 2022

(CC BY 4.0) | ISSN 2525-3409 | DOI: http://dx.doi.org/10.33448/rsd-v11i3.26188

Rolim, J. M. P. (2021). Percepções de mulheres multíparas sobre a vivência do trabalho de parto. RECIMA21 - Revista Científica Multidisciplinar - 2(6), e26418. doi https://doi.org/10.47820/recima21.v2i6.418

Sociedade Brasileira de Pediatria -SBP. 2020. Aleitamento Materno em tempos de COVID-19 - recomendações na maternidade e após a alta. https://www.sbp.com.br/fileadmin/user_upload/22467f-NA_-_AleitMat_tempos_COVID-19-_na_matern_e_apos_alta.pdf

Souto, S. A., Albuquerque, R. S., \& Prata, A. P. (2020). Fear of childbirth in time of the new coronavirus pandemic. Rev Bras Enferm. $73(2):$ e20200551. http://dx.doi.org/10.1590/0034-7167-2020-0551

Souza, K., Schneck, S., Pena, É., Duarte, E., \& Alves, V. (2020). Direitos humanos das mulheres no parto frente à pandemia de covid-19: o que fazer da enfermagem obstétrica. Cogitare Enfermagem, 25. http://dx.doi.org/10.5380/ce.v25i0.73148

Tostes, N. A., \& Seidl, E. M. F. (2016). Expectativas de gestantes sobre o parto e suas percepç̃os acerca da preparação para o parto. Temas em Psicologia, 24(2), 681-693. https://dx.doi.org/10.9788/TP2016.2-15

United Nations Children's Fund. 2020. Coronavirus disease (COVID-19): What parents should know. https:// www.unicef.org/stories/novel-coronavirusoutbreak-what-parents-should-know.

World Health Organization (WHO). (2018). WHO recommendations: intrapartum care for a positive childbirth experience. Geneva: WHO. https://www.who.int/ reproductivehealth/publications/intrapartum-care-guidelines/en/.

World Health Organization (WHO). 2020. Coronavirus disease (COVID-19): Situation Report - 195 https://www.who.int/docs/defaultsource/coronaviruse/situation-reports/20200802-covid-19-sitrep-195.pdf?sfvrsn=5e5da0c5_2 